\title{
Dark secrets of tobacco company exposed
}

This article was released by the Associated Press on 12 September 1998.

Because of its relevance to the American Medical Association report and the accompanying editorial published elsewhere in this issue of "Tobacco Control" (see pages 215 and 281), we are reproducing it here. $-E D$
Inside the restricted laboratory compound on the south coast of England, five senior scientists for BAT Industries, the world's second-biggest cigarette maker, were devising ways to make it harder for people to quit smoking.

At the start of the "brainstorming" session on 11 April 1980, Dr Robin A Crellin, the team research leader, offered an insight. "BAT should learn to look at itself as a drug company," he said, "rather than a tobacco company."

Just eight months earlier, BAT scientists had laid out some basic assumptions about cigarettes. A 28 Aug 1979 memo reads: "We are searching explicitly for a socially acceptable addictive product involving: a pattern of repeated consumption; a product which is likely to involve repeated handling; the essential constituent is most likely to be nicotine or a 'direct' substitute for it."

Public disclosure of once-secret industry documents has shown that Big Tobacco privately considered tobacco addictive and harmful at least four decades ago, even as it brushed aside claims that it manipulated nicotine in cigarettes to hook smokers.

Now, a review by the Associated Press (AP) of thousands of BAT documents-some stamped "CONFIDENTIAL," "SECRET," and "S-H-R-E-D" - offers new insight into the scale and sophistication of efforts to keep millions of users hooked on nicotine, and the motives driving a project that created a more addictive tobacco.

Taking the reader inside the onceimpregnable industry, the papers disclose:

- Why BAT lost its position as the world's No 1 cigarette maker to Philip Morris and its Marlboro brand in the 1960s (short answer: a nicotine breakthrough)

- Why BAT and its affiliates spent 17 years and tens of millions of dollars to create a new, nicotine-rich, harder-to-kick tobacco (to outdo Marlboro's nicotine technology and to produce more nicotine at lower cost)

- How vital it was to the industry to forestall broader government regulation of tobacco products - so vital that BAT's scientific and marketing efforts eclipsed reports by company researchers on the health dangers of nicotine.

BAT, formerly British American Tobacco, did finally develop its super-tobacco, a genetically altered variety with the code name Y-1.

This high-nicotine tobacco is used today by Brown \& Williamson Tobacco Corp., BAT's American subsidiary and the third largest US cigarette maker. Y-1 is in nine brands sold in the United States: Prime, Summit, Raleigh King Size, Raleigh 100s, Pall Mall Plain King Size, Lucky Strike Plains, Raleigh XLP, Private Stock and Richland.
BAT declined to comment on the documents, collected for Minnesota's recently settled lawsuit against cigarette makers. The British conglomerate referred questions to Brown \& Williamson.

Dr Sharon Boyse, director of scientific communications at Brown \& Williamson, said many of the research reports represented pure science with "no application in a commercial sense."

After being read passages from several documents, Boyse remarked: "A lot of these studies are experimental-to try to understand the underlying process of smoke chemistry - and may not necessarily turn into products."

However, the 5000 pages of memos, letters and reports-pulled by the AP from among 7 million BAT documents made public at the Minneapolis tobacco document repositoryshow that Y-1 tobacco became more than a theory.

The papers outline Y-1's creation, detailing not only the nuts-and-bolts science but the breezy chat at gatherings of researchers in locales such as Rio de Janeiro and Sydney, and the private strategy sessions of BAT's highest executives in London.

These are the Y-1 papers, and this is the story they tell.

The wording was as dry as a warning label on a cigarette pack.

But the conclusion of BAT nicotine report No RD-437-R became the basis for research that led to the invention of Y-1 tobacco.

It read: "Increased smoker response is associated with nicotine reaching the brain more quickly."

It meant: The faster nicotine reaches a smoker's brain, the bigger the drug rush - and the more likely the smoker will come back for more.

Dr JD Backhurst, who delivered the report on 30 September 1966, at BAT's laboratory in Southampton, England, had confirmed that nicotine exists in two chemical forms-not one, as had been generally assumed.

The first is the "bound" form, which the body has trouble absorbing.

The other is the "free" form, which passes instantly through the mouth, throat and lungs and into the bloodstream. Free nicotine reaches the brain faster, and, Backhurst demonstrated, gives the smoker a more addicting "kick."

If BAT wanted to make it tougher for people to give up its cigarettes, perhaps all the company needed to do was increase the free nicotine in them.

Philip Morris, BAT's competitor, already had discovered that by adding ammonia to its cigarettes, it could increase the ratio of free nicotine, and consequently the popularity of its 
Marlboro brand. In a few years, sales of Marlboro, with ammonia added, propelled Philip Morris past BAT to become the world's No 1 cigarette manufacturer.

BAT would research and use ammonia technology, too. To this day, it says ammonia was added to increase flavor. But the Y-1 papers show the company didn't want to just follow Philip Morris' innovations-BAT wanted to go one up on its rival.

To do that, it needed to know more about nicotine.

So BAT's scientists experimented with mice, squirrel monkeys, beagles and mechanical mouths. They stuck electrodes on adult smokers and measured changes in their brain waves and heart rate.

They swapped findings at conferences held wherever BAT had overseas subsidiaries: Germany, Italy, Australia, Canada, Brazil and the United States.

The objective was to "make the administration of nicotine better," wrote Dr SJ Green in a 2 March 1967 memo. That meant "making the administration pleasanter or more convenient" with fewer "undesirable physiological side effects."

The Y-1 papers show BAT scientists already had learned that nicotine- not just tar, as had been thought - did bad things to people's arteries, hearts and brains.

"Certain medical studies would seek to blame nicotine for cardiovascular disease," Dr DJ Wood, a senior BAT scientist, wrote for a nicotine presentation to BAT executives in Chelwood, England, in September 1969.

Most of the studies were BAT's own. Later BAT research turned up something even uglier-that nicotine might contribute to cancer.

Notes from a 5 February 1979 research conference in England read: "In the B14 experiment using three levels of nicotine citrate, the high nicotine is more tumorigenic (tumor-creating) and possibly more malignant."

Nine years later, an abstract of another BAT study, "Mutagenicity of cigarettes containing added nicotine," suggested a link between nicotine and carcinogens in tobacco smoke.

Independent studies have since confirmed the danger. Although nicotine is not a carcinogen in its own right, other chemicals in burned tobacco convert some nicotine into a carcinogen, said Jack Henningfield, an addiction specialist at the Johns Hopkins Medical School.

For BAT, this raised a worrisome question: what if governments ordered cigarette makers to reduce nicotine in their products?

Twelve scientists from five countries met at an inn in the Florida Keys, surrounded by lagoons, palm trees and the turquoise surf. It was a healthy setting for BAT's January 1974 conference on how to make a "safe" cigarette.

The researchers discussed techniques to remove carcinogens from tobacco smoke: asbestos filters; microscopic holes in the cigarette paper to dilute the smoke; synthetic nicotine substitutes; even a "noninhalable cigarette."

None of these ideas ever worked. The Y-1 papers suggest that by the late 1970s, BAT had all but given up on making a "safe" cigarette. Dr Robert A Sanford, then Brown \& Williamson's vice president of research, even discouraged toxicological testing of cigarette smoke in an 18 August 1980 letter to Dr Alan Heard at BAT's Southampton research center.

Research into "irritation and inhalation of smoke," he wrote, was a "dangerous area. Do not publish or circulate."

It didn't abandon nicotine. That's why smokers smoked.

"If the nicotine delivery is reduced below a threshold 'satisfaction' level, then surely smokers will question more readily why they are indulging in an expensive habit," wrote Green, the senior BAT scientist, on 29 March 1976.

He recommended the company divert attention from nicotine's health risks and frame the public health debate around the dangers of tar. "It is advocated that every opportunity is taken to separate tar and nicotine in the minds of consumers and legislators."

The fear that public health officials might press for drastic reduction of nicotine was so great that some BAT scientists even suggested the company diversify into other "moodaffecting" substances: marijuana, tranquilizers and the like.

That never happened, but during the 11 April 1980 brainstorming session at BAT's Southampton laboratory, Crellin noted that, one day, such drugs might be "“socialized' like alcoholic drinking and tobacco smoking."

There was another way BAT could address its fear of nicotine regulation. It could change the form of nicotine in cigarettes.

BAT knew that government regulators, when measuring nicotine deliveries in tobacco products, do not distinguish between the highly addictive, free nicotine and the less addictive, bound nicotine.

So, if BAT could chemically convert more of the bound nicotine in its products to free nicotine, it wouldn't need to put as much nicotine in cigarettes to keep smokers hooked. In fact, it could promote a nicotine "reduction" while actually giving cigarettes more nicotine kick.

Marlboro's success proved the theory. Philip Morris had added ammonia, causing the conversion and giving smokers a stronger nic-kick, which drove up sales.

BAT also began using ammonia in its products, but found only a limited amount could be used without making the smoke "very noxious," according to a 22 October 1979 Brown \& Williamson research report.

Dr TR Shori, its author, suggested that free nicotine in cigarettes might be increased by altering the tobacco leaf itself. A high-nicotine tobacco, he said, could cause "more nicotine to be available to the smoker as free nicotine."

"We could develop an ultra-low-tar cigarette that produced considerably more impact than its delivery level (nicotine, as measured by the government) would suggest," he wrote.

And governments would be clueless. 
To play its shell game, BAT needed a high-nicotine tobacco. The corporate giant turned for help to a smalltime tobacco grower, Lloyd Vernon Jones, and his 18-acre farm in Stantonsburg, North Carolina. It was the summer of 1977, and farmers in America's Southern tobacco belt were worried. Public health advocates were railing against tobacco; cigarette consumption in the United States was falling.

So when a representative for Brown \& Williamson showed up at Jones' ranch house and offered to pay him handsomely to grow some new plants rich in nicotine, the farmer obliged.

Tobacco genetics were about to take a quantum leap: the five "Virginia" tobacco varieties sprouting in Jones' fields had been genetically cross-bred to produce twice the nicotine of regular leaf.

Two of the plant lines lived to maturity. Brown \& Williamson code-named them Y-1 and Y-2 (the latter was eventually supplanted by $\mathrm{Y}-1$ ). Then, in 1983, it quietly took them away.

What happened to the tobacco once it left the Jones farm? The Food and Drug Administration (FDA) figured out part of the story in the spring of 1994.

The agency learned that Brown \& Williamson had taken Y-1 to DNA Plant Technology, or DNAP, a biotech company in Cinnaminson, New Jersey. DNAP did more genetics work to increase Y-1's yield and disease resistance.

The FDA also learned that Y-1 was grown in Brazil and then used in five Brown \& Williamson brands sold in the United States. Although this was legal, the agency was concerned enough to disclose its findings to Congress in June 1994.

Brown \& Williamson said it was only trying to make cigarettes safer, but, concerned about bad publicity, agreed to stop using Y-1.

But last December, the AP reported it had found tons of Y-1 and related high-nicotine strains being cultivated in Brazil for the world market by Souza Cruz, BAT's Brazilian subsidiary. In February, the AP reported Brown \& Williamson had resumed the use of high-nicotine tobaccos in American cigarettes in 1995. This time, Brown \& Williamson said it would stop using Y-1 by 1 April 1999.

The Y-1 papers, however, show the project was much bigger than previously known-a global operation coordinated by the highest executives at BAT Industries' world headquarters in London.

The "Tobacco Strategy Review Team" sessions included Sir Patrick Sheehy, who retired as chairman in 1996; Martin Broughton, BAT Industries' present chairman; Ulrich Herter, now the managing director of BAT Industries; and RJ Pritchard, a former Brown \& Williamson chairman and former member of BAT Industries' board of directors.

Chairmen of BAT's subsidiaries in England, Germany, Brazil and Canada also participated in the meetings. BAT declined an AP request to interview the executives.
Brown \& Williamson ran the project, said Boyse, though "often, BAT Industries would act as a coordination point."

Under pressure to outdo Philip Morris' ammoniated Marlboro cigarettes, BAT pushed its Y-1 project into high gear in 1983.

High-nicotine seed and pollen were assigned code numbers and shipped from the United States to affiliates around the world: Brazil, Canada, Germany, Honduras, Chile, Venezuela, Zimbabwe, Nigeria and Pakistan, the Y-1 papers show.

Brown \& Williamson didn't apply for the special US customs permit required to export tobacco seed and pollen, according to the US Department of Agriculture.

The project didn't stop with mild, Virginia leaf. DNAP, the biotech company, also transferred nicotine-making genes from Y-1 and Y-2 into "burley" tobacco, the coarser leaf used in cigar, pipe and chewing tobacco.

The new burley varieties packed $50-75 \%$ more nicotine than the old lines, according to a 25 April 1990 DNAP memo. This high-nicotine burley was also used in cigarettes sold in the United States, the Y-1 papers show.

Accounting memos show that between 1985 and 1991, Brown \& Williamson grew at least 142700 pounds [64 $700 \mathrm{~kg}$ ] of $\mathrm{Y}-1$ and additional quantities of its Burley cousins in North Carolina, Kentucky, New Jersey and California-ignoring a price-support agreement between tobacco companies and the government not to grow high-nicotine tobacco on American soil.

In the end, southern Brazil became the place for major production, the Y-1 papers show.

Making Y-1 tobacco wasn't cheap: the seed cost $\$ 2200$ a pound (BAT would eventually spend a total of $\$ 4$ million producing seed). Research was costly; in 1989 alone, it totaled $\$ 9$ million, the documents show.

With travel, meetings, field surveys, farm subsidies, shipping, patent applications, taste testing, studies and other work, costs may have climbed into the tens of millions of dollars.

Boyse said she did not know how much money was spent on the entire Y-1 project.

Because Y-1's yield was lower than regular Virginia leaf, Souza Cruz had to pay Brazilians $55 \%$ more for Y-1 than natural leaf, according to company correspondence.

The documents suggest BAT regarded it as money well spent.

"Y-1 gives 50 percent more nicotine per acre even with 20 percent less leaf yield," read a 14 May 1990 memo from Brown \& Williamson's research department.

By 1987, Y-1 tobaccos were shipped to Finland, Norway, England, Germany and Switzerland, and then to France, Malaysia and Australia, for consumer trials. There was just one problem.

Even when blended with weaker tobaccos, Y-1 leaf packed too sharp a nicotine "jolt."

"Y-1 Lights products may be too strong for lights smokers," wrote Lynn A Walker, a Brown \& Williamson researcher, in a 17 September 1990 memo. 
If BAT didn't do something to spread out Y-1's nicotine more uniformly in a puff, the project might end up a colossal failure.

Then a breakthrough came, quite literally, out of thin air.

The technique that made Y-1 more palatable - and profitable-was discovered inside BAT's Southampton laboratory in late 1990. It's known to scientists as "the expansion process."

This involves heating shreds of cured tobacco with liquid carbon dioxide in a chamber. The carbon dioxide turns to vapor and puffs the dry tobacco up like Rice Krispies.

Cigarette makers expand tobacco to save money by giving customers more air and less leaf. Less tobacco is supposed to mean the smoker gets less tar and nicotine.

Y-1 reacted differently when bulked up. Not only did Y-1 retain its nicotine power, it released nicotine more gradually as it burned, giving the user a smoother smoke. Sure enough, BAT taste testers liked cigarettes blended with expanded Y-1.

The discovery pumped new life into the project.

During the next three years, BAT did at least three major studies on Y-1's impact on the body. Its subsidiaries started adding expanded Y-1 to cigarettes in 1992, and by 1994 some $\$ 18.2$ million worth of Y-1 leaf had been stockpiled in Brazil and the United States, according to a 9 June 1994 Brown \& Williamson memo.

On 8 March 1994 BAT reviewed Y-1 tobacco's effects on smokers.

Nineteen copies of report No P-35 were distributed to BAT executives in England, Brazil, Germany and the United States. Each page carried the warning, "Do not copy or show to unauthorized persons."

Dr PC Bevan, the author, wrote that he hoped his report would "assist in pointing the way towards being able to manipulate and modify the impact" of nicotine on smokers, and proceeded to lay out the results of two experiments- "Project NATO" and "Project FELT"-in which testers had smoked cigarettes blended with Y-1 tobacco.

His conclusion: Y-1 leaf was special because, unlike natural leaf, it had a lower proportion of tar to nicotine. The sticky tar compounds-the same ones that cause cancer-block nicotine from entering the bloodstream, he explained. Without all the tars, Y-1's extra nicotine was absorbed faster.

"Increased nicotine delivery," he wrote, occurred because the throat and lungs were "less protected by the tar" from the nicotine.

"Technically, Bevan may be correct," said Boyse of Brown \& Williamson.

But the test cigarettes referred to in the report, she said, were nothing like the ones that went to market. Those cigarettes, she said, would have "tasted like a cigar."

Bill Farone, a former Philip Morris research director, reviewed the Bevan report at the request of the $\mathrm{AP}$ and offered a different interpretation.

"BAT was figuring out how to increase the drug-rush sensation of nicotine without ammonia," he said, countering Boyse. "What they were doing was making their cigarettes more addictive."

Thirty-seven days after Bevan's "manipulate and modify" report, the chief executive officers [CEOs] of America's seven biggest tobacco companies stood side by side and took an oath to tell the truth to a committee of the US House of Representatives.

That spring morning, 14 April 1994, the CEOs were asked, for the record, whether they believed nicotine was addictive.

One by one, they said no. Thomas E Sandefur, the chief executive of Brown \& Williamson, was sixth. "I believe that nicotine is not addictive," he said.

Sandefur, who died in 1996, was called back to testify before the committee on 27 June 1994. "Do you manipulate the nicotine levels of your cigarettes?" asked Representative Tom Bliley of Virginia.

"We do not manipulate the nicotine levels of our cigarettes," Sandefur replied. "No, sir."

$$
\begin{array}{r}
\begin{array}{r}
\text { TODD LEWAN } \\
\text { Associated Press }
\end{array} \\
\star \star \star \star
\end{array}
$$

\section{BAT speaks out on nicotine}

Associated Press, 12 September 1998

Statements on nicotine from internal files of Brown E Williamson Tobacco Corp. and other affiliates of the British conglomerate, BAT Industries plc; these were among subpoenaed materials made public in state lawsuits against cigarette makers:

"It is possible to remove all of the nicotine from tobacco, but it has been our experience that the resulting cigarette or cigar is an emasculated product which is neither palatable nor satisfying to the smoker."-HR Hanmer, BAT research director, 14 October 1955.

"Moreover, nicotine is addictive. We are, then, in the business of selling nicotine, an addictive drug effective in the release of stress mechanisms."-Addison Yeaman, Brown \& Williamson vice president and general counsel, 1963.

"I think that we can say even now that we can regulate, fairly precisely, the nicotine and sugar levels to almost any desired level management might require."-Dr RB Griffith, Brown \& Williamson official, 18 September 1963.

"Smoking is an addictive habit attributable to the nicotine and the form of nicotine affects the rate of absorption."-BAT Research and Development Conference minutes, 24 October 1967.

"We are in the business of selling nicotine so why not produce the first 'TRUELY [sic] SATISFYING LOW TAR CIGARETTE??"-Brown \& Williamson in-house slide presentation, 14 August 1974.

"Taking a long-term view, there is a danger in the current trend of lower and lower cigarette (nicotine) deliveries-i.e. the smoker will be weaned away from the habit."-Dr SJ Green, BAT scientist, 29 March 1976.

"There are other things about tobacco though. It is legal (as is alcohol but not 
marijuana and LSD), and the articles themselves are eminently portable. It can be used freely in public places in most countries. . . . However it has drawbacks. The major one is that it has a 'health shadow' over it which is not easy to dispel. Secondly, it is a messy habit, polluting the non-smoker's breathable atmosphere, and leaving ash and debris, not to mention smells, around for hours or days. Thirdly, carelessly used, it sets fire to things."-CC Greig, BAT scientist, 1979.

"If the FDA were to ever obtain jurisdiction over cigarettes under the current regulatory framework, it would be virtually impossible to pass these FDA screens. As a result, FDA jurisdiction could be tantamount to a marketing preclusion. We obviously need to make sure that we don't do anything in the nicotine delivery device area which could lead to the FDA nicotine delivery device area which could lead to the FDA
asserting or obtaining jurisdiction over cigarettes."-Mick McGraw, Brown \& Williamson official, 24 April 1992.

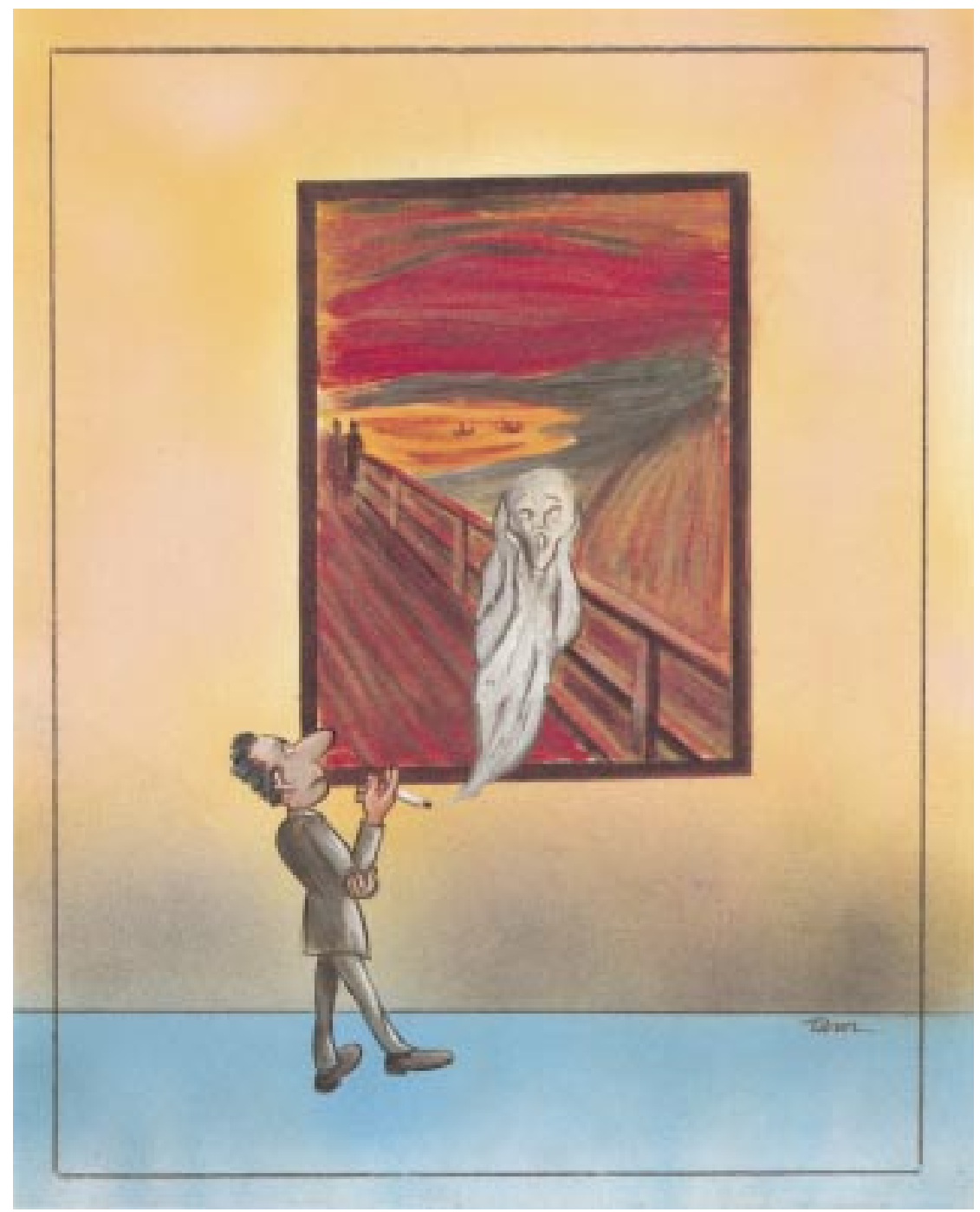

By Turan Aşan (Turkey). 